\title{
Effect of precursors on the microstructure and electrical properties of $\mathrm{Bi}_{2} \mathrm{Ba}_{2} \mathrm{Co}_{2} \mathrm{O}_{x}$
}

\author{
A. Sotelo, M. A. Torres, Sh. Rasekh, M. A. Madre, J. C. Diez \\ Instituto de Ciencia de Materiales de Aragón (CSIC-Universidad de Zaragoza), Ma \\ de Luna, 3. 50018-Zaragoza, Spain.
}

\begin{abstract}
$\mathrm{Bi}_{2} \mathrm{Ba}_{2} \mathrm{Co}_{2} \mathrm{O}_{\mathrm{x}}$ thermoelectric materials have been prepared through three different synthesis methods. The corresponding precursors were obtained from a coprecipitation method using oxalic acid, attrition milling, and classical solid state method (used as reference). Microstructural studies of precursors have shown that the ones produced by coprecipitation and attrition milling led to smaller grain sizes than the ones obtained through ball milling. Infrared spectroscopy has demonstrated that a thermal treatment at $450{ }^{\circ} \mathrm{C}$ totally decomposes the metallic oxalates, producing a mixture of $\mathrm{Bi}$ and $\mathrm{Co}$ oxides, and $\mathrm{Ba}$ carbonate, the same average composition of the other precursors. After sintering procedure, it has been determined that the small grain size precursors produce high density samples, reflected in a decrease of electrical resistivity without significant modification of Seebeck coefficient. As a consequence, power factor values are more than two times higher than the measured in samples prepared by the classical solid state method. Moreover, the highest power factor values are in the order of the best reported in textured materials, demonstrating the critical role of precursors in the final properties of these materials.
\end{abstract}

Keywords: Ceramics; Synthesis; Microstructure; Thermoelectric properties. 
* Corresponding author: A. Sotelo

E-mail: asotelo@unizar.es

Address: Instituto de Ciencia de Materiales de Aragón (CSIC-Universidad de

Zaragoza); C/Mª de Luna, 3; 50018-Zaragoza; Spain

Tel: +34976762617

Fax: +34 976761957

\section{Acknowledgements}

The authors wish to thank the Gobierno de Aragón-FEDER (Grupos de Investigacion Consolidados T12 and T87) and MINECO-FEDER (MAT2013-46505C3-1-R) for financial support. Authors would like to acknowledge the use of Servicio General de Apoyo a la Investigación-SAI, Universidad de Zaragoza. 


\section{Introduction}

Thermoelectric (TE) materials are characterized by their capability to directly transform thermal to electrical energy. Nowadays, they are considered one of the most promising methods to fight against global warming, decreasing the $\mathrm{CO}_{2}$ emissions in numerous energy transforming systems by increasing their efficiency. Moreover, they can also be used for clean energy generation from solar radiation [1]. Nevertheless, before massive applications, these materials should possess high efficiency at working temperatures, which is quantified with ZT (dimensionless figure-of-merit). ZT is calculated from the $\mathrm{TS}^{2} / \rho \kappa$ expression, where $\mathrm{T}, \mathrm{S}, \rho$, and $\kappa$, are absolute temperature, Seebeck coefficient, electrical resistivity, and thermal conductivity, respectively [2]. On the other hand, the electrical part of this equation $\left(S^{2} / \rho\right)$, called power factor, $\mathrm{PF}$, is often used to determine the performances of these materials.

Nowadays, different materials show high performances at their working temperatures, as $\mathrm{Bi}_{2} \mathrm{Te}_{3}$, or $\mathrm{PbTe}[3,4]$. However, they cannot work at high temperatures as they can melt or oxidize when working under air, drastically limiting their practical applications. These temperature limitations were surpassed in 1997 by the discovery of attractive thermoelectric properties in $\mathrm{Na}_{x} \mathrm{CoO}_{2}$ [5], leading to intense research work in CoO-based materials [6-9], with high working temperatures. Moreover, all these CoO-based materials are characterized by a large anisotropy, which has been exploited to raise the performances of anisotropic materials through grain alignment techniques [10-13] to obtain thermoelectric performances close to the achieved in single crystals. Furthermore, doping processes have been also applied to tailor their properties [14-16] by modifying the 
$\mathrm{Co}^{3+} / \mathrm{Co}^{4+}$ relationship in the conducting layer, in agreement with Koshibae's expression [17].

On the other hand, there is not enough work performed on the effect of preparation routes on the properties of these ceramic materials, while it is well known that the precursors play a critical role on the performances of sintered bodies. Most of the precursors used to prepare these ceramics are obtained via the classical solid state route [10], which usually leads to incomplete reactions, and compositional inhomogeneities, among others. These problems can be solved using other precursors preparation methods, typically the well-known sol-gel ones $[11,18,19]$. On the other hand, other promising processes $[20,21]$ are not very often applied, as they need more work to be optimized.

In this work, two different synthesis methods which produce precursor powders with very high surface/volume relationship will be studied and compared with the classical solid state route. These two processes are: coprecipitation with oxalic acid, and attrition milling. The advantage of the first method is the intimate mixture of cations in the precipitate, while the second one is adequate to produce small particle sizes in much higher amounts than the first one. The final bulk properties will be determined, related with the microstructure, and compared with those obtained on solid state prepared samples.

\section{Experimental}

The initial $\mathrm{Bi}_{2} \mathrm{Ba}_{2} \mathrm{Co}_{2} \mathrm{O}_{x}$ precursors were prepared through the following methods:

(i) Coprecipitation: Appropriate proportions of $\mathrm{Bi}_{2} \mathrm{O}_{3}$ (99.9\%, Aldrich), $\mathrm{BaCO}_{3}$ (99.98\%, Aldrich), and $\mathrm{Co}\left(\mathrm{NO}_{3}\right)_{2} \cdot 6 \mathrm{H}_{2} \mathrm{O}(\geq 99 \%$, Aldrich) commercial powders were dissolved in a mixture of $\mathrm{HNO}_{3}$ (Panreac, PA) and distilled water. Oxalic acid 
(Panreac, $\geq 99.5 \%$ ) was added to the above solution in the adequate amount, reaching a $\mathrm{pH}$ value of 0.4 . Moreover, $30 \mathrm{wt} \% \mathrm{NH}_{3}$ solution in water (Panreac, PA) and $\left(\mathrm{NH}_{4}\right)_{2} \mathrm{CO}_{3}$ (Panreac, PRS-CODEX) have been added to adjust $\mathrm{pH}$ at 8.8 to completely precipitate all cations, in agreement with the results obtained in closely related systems [22]. The resulting suspension was aged during 15 minutes at 75 ${ }^{\circ} \mathrm{C}$ with continuous stirring, followed by filtering and washing the light pink precipitate. After drying at $\sim 150^{\circ} \mathrm{C}$, the precipitate was heated at $450{ }^{\circ} \mathrm{C}$ for $1 \mathrm{~h}$ to decompose the oxalates, followed by calcination in two steps, at 700 and $750{ }^{\circ} \mathrm{C}$ for $12 \mathrm{~h}$ with an intermediate manual milling, to decompose the carbonates.

(ii) Attrition milling: $\mathrm{Bi}_{2} \mathrm{O}_{3}\left(99.9 \%\right.$, Aldrich), $\mathrm{BaCO}_{3}\left(\geq 99.98 \%\right.$, Aldrich), and $\mathrm{Co}_{3} \mathrm{O}_{4}$ (99.5\%, Panreac) were mixed and attrition milled in water, using $1 \mathrm{~mm}$ diameter $\mathrm{ZrO}_{2}$ balls, for $3 \mathrm{~h}$ at $600 \mathrm{rpm}$. The suspension was then sieved, to separate the $\mathrm{ZrO}_{2}$ balls and the powders mixture, and dried using infrared radiation. The homogeneous mixture was calcined at 700 and $750^{\circ} \mathrm{C}$ for $12 \mathrm{~h}$, with an intermediate manual milling, to decompose the carbonates.

(iii) Classical solid state method: $\mathrm{Bi}_{2} \mathrm{O}_{3}\left(99.9 \%\right.$, Aldrich), $\mathrm{BaCO}_{3}(\geq 99.98 \%$, Aldrich), and $\mathrm{Co}_{3} \mathrm{O}_{4}(99.5 \%$, Panreac) were mixed and milled in an agate ball mill for 30 minutes at $300 \mathrm{rpm}$ in acetone media. The slurry was then sieved to separate the agate balls and the powders mixture, followed by drying under infrared radiation. The powders were calcined twice at 700 and $750{ }^{\circ} \mathrm{C}$ for $12 \mathrm{~h}$, with an intermediate manual milling, to decompose the carbonates.

After calcining processes, samples were uniaxially pressed at $400 \mathrm{MPa}$ in form of pellets of $3 \times 3 \times 14 \mathrm{~mm}^{3}$ and sintered at $750^{\circ} \mathrm{C}$ for $24 \mathrm{~h}$ with a final furnace cooling. After sintering, the samples show a different shrinkage depending on the sintering procedure, leading to sizes of around $2.50 \times 2.62 \times 12.45,2.63 \times 2.66 \times 12.84$, and 
$2.76 \times 2.81 \times 13.05 \mathrm{~mm}^{3}$ for the coprecipitation, attrition milling, and classical solid state samples, respectively Hereafter, samples produced by coprecipitation will be named $\mathrm{P} 1$, by attrition milling, P2, and by classical solid state, P3.

The precursors characterization has been performed all along the process using DTA-TGA (TA Instruments, SDT Q600) under air between room temperature and $800^{\circ} \mathrm{C}$, and FTIR (Bruker Vertex 70 ) to identify the intermediate products.

Moreover, their microstructural and grain size evolution has been studied in a Field Emission Scanning Electron Microscope (FESEM, Carl Zeiss Merlin) using secondary electrons under an applied voltage of $3 \mathrm{KV}$.

In sintered materials, phase identification has been performed through powder Xray diffraction (XRD) in a Rigaku D/max-B X-ray powder diffractometer (CuK $\alpha$ radiation) with $2 \theta$ ranging between 5 and 60 degrees. Microstructural observations were performed on polished surface sections of samples using backscattered electrons under an applied voltage of $20 \mathrm{KV}$ in a FESEM equipped with an energy dispersive spectrometer (EDS) to determine the elemental composition of each phase. Furthermore, grain sizes were estimated through several micrographs using the line intercept technique. Electrical resistivity and Seebeck coefficient were simultaneously measured by the standard dc four-probe technique in a LSR-3 system (Linseis $\mathrm{GmbH}$ ) between 50 and $650^{\circ} \mathrm{C}$. Furthermore, with the electrical resistivity and Seebeck coefficient data, $P F\left(=S^{2} / \rho\right)$ has been calculated to determine the TE performances of each sample. Finally, density of the different samples has been determined using the Archimedes method in, at least, four samples of each synthesis method, taking $7.20 \mathrm{~g} / \mathrm{cm}^{3}$ as theoretical density [23].

\section{Results and discussion}




\section{Precursors}

FTIR characterization

FTIR spectra obtained in representative samples are displayed in Fig. 1. The study of the absorbance bands in the dry precipitate (Fig. 1a) has shown the formation of $\mathrm{Bi}, \mathrm{Ba}$, and $\mathrm{Co}$ oxalates. These bands are identified in Fig. 1a by the corresponding cation, in agreement with previously published data [24]. After thermal treatment at $450^{\circ} \mathrm{C}$, the spectrum drastically changes (see Fig. 1b), showing the decomposition of oxalates and the formation of barium carbonate, indicated in Fig. 1b by the corresponding cation [24]. The other cations are not observed in the spectrum as they are forming Bi and Co oxides [25]. This spectrum is also the same obtained in the P2 and P3 dry mixtures. The thermal treatment at $700^{\circ} \mathrm{C}$ promotes the $\mathrm{BaCO}_{3}$ decomposition, which is partial in the P3 samples (see Fig. 1c), while it is nearly complete in the P1, and P2 ones (see Fig. 1d). As a consequence, the second thermal treatment at $750^{\circ} \mathrm{C}$ is necessary to totally decompose this carbonate, as illustrated in Fig. 1e for the classically prepared precursors.

\section{Microstructural characterization}

SEM observations of precursor powders in the first stages of preparation are displayed in Fig. 2. Fig. 2a shows the aspect of the precipitated oxalates, formed by large grains, indicating that the followed procedure has formed a limited number of nucleation centers which grow during the precipitation process, in agreement with previous results [21]. This structural feature clearly favours the easy separation of remaining liquid and the precipitate, avoiding materials losses. When the precipitate is subjected to a thermal treatment at $450^{\circ} \mathrm{C}$ for one hour, the oxalates are decomposed and the mixture is formed by barium carbonate, and $\mathrm{Bi}$, and $\mathrm{Co}$ oxides, the same composition determined for the P2, and P3 precursors, according 
to FTIR data. In this stage, all three samples show clear differences between them (see Figs. 2b, c, and d). P1 precursors are composed of large agglomerates of very small particles (> $50 \mathrm{~nm}$ ). On the other hand, P2 precursors are formed by a mixture of large and small particles, while P3 has a more regular size distribution but larger grain sizes. These microstructural features have been reflected in the partial $\mathrm{BaCO}_{3}$ decomposition at $700^{\circ} \mathrm{C}$ in $\mathrm{P} 3$ precursors, while it is nearly complete in the other two, observed in the FTIR results. These differences can be easily associated to the different grain sizes of precursors in this processing step, as lower grain sizes imply larger surface area and reactivity.

After calcining procedure, the powders microstructure is totally modified, as illustrated in Fig. 3. As it can be easily observed, the higher reactivity of P1, and P2 powders promote a very important grain growth leading to higher grain sizes than the ones observed in P3 samples. Moreover, the intimate mixture of cations produced through the coprecipitation process is also reflected in the lower amount of very small unreacted grains found in the surface of the platelets, compared with the attrition samples (compare Figs. 3a, and b). Consequently, after calcining procedure it seems that $\mathrm{P} 1$ process leads to the most homogeneous precursors among the three procedures.

\section{Sintered materials}

\section{XRD characterization}

Powder XRD patterns performed on sintered samples produced through the three synthesis methods are presented (from 5 to 40 degrees for clarity) in Fig. 4. The data represented in the graph clearly show that all samples possess similar patterns and all peaks indexed in the plot correspond to the $\mathrm{Bi}_{2} \mathrm{Ba}_{2} \mathrm{Co}_{2} \mathrm{O}_{x}$ phase $[26,27]$. Moreover, no other phases have been identified in any of the samples, indicating 
that the amount of secondary phases should be very small or, in other case, their peaks could be overlapped with those of the thermoelectric phase.

\section{Microstructural characterization}

SEM micrographs of representative polished surfaces of sintered materials prepared from the different precursors are displayed in Fig. 5. In these images it can be clearly seen that all the sintered samples show the typical microstructure of sintered materials, formed by randomly oriented plate-like grains. Other interesting observation which can be made comparing these micrographs is that $\mathrm{P} 1$ samples possess lower porosity than the other ones. Careful observation of their microstructures has shown that all samples are composed of different phases (distinguished by their different contrast). These phases are numbered for clarity, \#1 corresponds to the thermoelectric $\mathrm{Bi}_{2} \mathrm{Ba}_{2} \mathrm{Co}_{2} \mathrm{O}_{x}$ (major phase in all the samples, grey contrast), accompanied by \#2 (cobalt oxide, black contrast) in P2 samples, and \#3, and \#4 (Bi-Ba, and Ba-Co oxides, bright, and dark grey contrasts, respectively) in P3 ones. These microstructural differences clearly reflect the influence of initial grain sizes and homogeneity of precursors. As it is well known, coprecipitation processes lead to an intimate mixture of cations and, consequently easily produces single $\mathrm{Bi}_{2} \mathrm{Ba}_{2} \mathrm{Co}_{2} \mathrm{O}_{x}$ phase. On the other hand, attrition milling decreases the initial grain sizes, increasing their reactivity, and leading to nearly pure phase materials, while the classical solid state route produces the highest amount of secondary phases due to the larger grain sizes of precursors, as evidenced in the previous sections. The thermoelectric phase content in the different samples has been determined through image analysis in several micrographs, confirming these observations, with values around 94,88 , and $80 \%$ for the P1, P2, and P3 samples, respectively. Moreover, the estimated grain sizes in the sintered bodies for each 
synthesis method, $5.8 \pm 0.4,6.8 \pm 0.5$, and $4.5 \pm 0.5 \mu \mathrm{m}$ for $\mathrm{P} 2, \mathrm{P} 1$, and $\mathrm{P} 3$ samples, respectively, agrees with these previous observations.

\section{Thermoelectric characterization}

The measured thermoelectric properties in the samples prepared in this work, as well as the reported in the literature, are summarised in Table 1 for a clear comparison of the different parameters.

Electrical resistivity data displayed in Fig. 6 show metallic-like behaviour for all samples $(\mathrm{d} \rho / \mathrm{dT}>0)$, with values clearly reflecting the microstructural features previously discussed. Electrical resistivity drastically decreases for P1 and P2 samples, compared with P3 ones, due to their higher content of thermoelectric phase, in agreement with previously published data [28]. Moreover, P1 samples show lower resistivity than P2 ones, due to their lower porosity (see Figs. 5a, and b) promoted by the intimate mixture of the different cations in the P1 precursors. These observations have been confirmed through density measurements of these sintered materials, which showed the values: $91 \pm 2,85 \pm 3$, and $78 \pm 2 \%$ of the theoretical one for the P1, P2, and P3 samples, respectively. The minimum values at room temperature measured in P1 samples are much lower than the generally obtained in sintered materials $[29,30]$ and comparable to the determined in textured samples [9,31-33]. Furthermore, they are not far from the reported values in single crystals along the ab plane. At high temperatures $\left(650^{\circ} \mathrm{C}\right), \mathrm{P} 1$ samples still display the lowest values which are about one half of the best measured ones in classically sintered materials [30] but slightly higher than the reported for textured materials $[9,31,33]$. It is also worth to mention that the electrical resistivity values obtained in this work have been measured in samples composed of randomly oriented grains 
which should present much higher electrical resistivity than textured samples due to the high anisotropy of these materials.

Fig. 7 displays the variation of the Seebeck coefficient as a function of temperature for samples prepared from the different precursors. All of them exhibit positive values in the whole studied temperature range, confirming a dominating hole conduction mechanism. Moreover, they show the same behaviour reported for this kind of materials, $S$ is increased when the temperature is raised in all cases [36]. On the other hand, P1 and P2 samples exhibit a practically linear increase with temperature, corresponding to a degenerated semiconductor or metallic behaviour, while P3 ones differ from this evolution probably due to the presence of a higher amount of secondary phases. Furthermore, P3 samples possess slightly higher S values than the other ones, in agreement with the electrical resistivity data. The room temperature values measured in these samples are very similar (see Table 1) indicating a similar $\mathrm{Co}^{3+} / \mathrm{Co}^{4+}$ relationship and a $\mathrm{Co}^{4+}$ fraction of 0.7 using Koshibae's equation [17]. The highest values at room temperature are higher than the reported in sintered materials $[29,30]$, and slightly lower than the measured in textured materials [9,31-33], or single crystals [34,35]. Moreover, at high temperatures $\left(650^{\circ} \mathrm{C}\right)$, the maximum values measured in this work are higher than the reported in textured materials $[9,31,33]$, and still much higher than the obtained in sintered materials [30].

PF variation with temperature has been calculated from the electrical resistivity and Seebeck coefficient values, and presented in Fig. 8. In the graph, it can be easily observed that P1 and P2 samples show very high PF values, compared with P3 ones. This effect is due to the already mentioned effect of small precursors grain sizes, reflected in higher homogeneity, and density, together with lower amount of 
secondary phases. Moreover, the improvement of P1 samples, compared with P2 ones can be explained by the intimate mixture of cations produced in the coprecipitation process. The highest PF values at room temperature are more than two times higher than the obtained in P3 samples, and much higher than in sintered materials $[29,30]$. Moreover, they are in the order of textured materials [9,31-33], although lower than the reported in single crystals $[34,35]$. On the other hand, at high temperatures $\left(650^{\circ} \mathrm{C}\right)$ the highest values are much higher than the typical reported in sintered materials [30], and in the order of the obtained in textured materials $[9,33]$, with the only exception of textured rods grown at very low rates (5 $\mathrm{mm} / \mathrm{h})[31]$.

Finally, it is important to highlight that the high PF determined in this work has been obtained in sintered samples with randomly oriented grains, nearly reaching the values obtained in well textured samples. From these results, it is possible to conclude that precursors play a critical role in the final performances of these thermoelectric materials. As a consequence, it is necessary to carefully select the preparation routes to obtain high performances materials for practical applications in high temperature thermoelectric devices.

\section{Conclusions}

$\mathrm{Bi}_{2} \mathrm{Ba}_{2} \mathrm{Co}_{2} \mathrm{O}_{x}$ thermoelectric materials were successfully prepared by three different synthesis methods: coprecipitation with oxalic acid, attrition milling, and classical solid state method. Microstructural studies of precursors have shown that coprecipitation and attrition milling methods lead to much lower particle sizes than the classical solid state one. The decrease of particle sizes in the precursors lead to higher density and phase purity materials after the sintering procedure due to their 
higher reactivity. These microstructural improvements are clearly reflected in the decrease of electrical resistivity without significative decrease of Seebeck coefficient. As a result, the highest PF values obtained in this work are much higher than the reported in sintered materials. Moreover, they are comparable to the typical ones measured in textured materials, being only surpassed by materials grown at very low rates and single crystals. As a consequence, it has been demonstrated that the selection of an adequate synthesis method plays a critical role in the final performances of $\mathrm{Bi}_{2} \mathrm{Ba}_{2} \mathrm{Co}_{2} \mathrm{O}_{x}$ materials. 


\section{References}

1. Elsheikh, M. H., Shnawah, D. A., Sabri, M. F. M., Said, S. B. M., Hassan, M. H., Bashir, M. B. A., Mohamad, M.: A review on thermoelectric renewable energy: Principle parameters that affect their performance. Renew. Sust. Energ. Rev. 30, 337-355 (2014).

2. Rowe, D. M.: Thermoelectrics Handbook: Macro to Nano. CRC Press, Boca Raton (2006).

3. Santamaria, J. A., Alkorta, J., Sevillano, J. G.: Mechanical properties of bismuth telluride $\left(\mathrm{Bi}_{2} \mathrm{Te}_{3}\right)$ processed by high pressure torsion (HPT). Bol. Soc. Esp. Ceram. V. 52, 137-142 (2013).

4. Wang, H. C., Hwang, J., Snedaker, M. L., Kim, I.-H., Kang, C., Kim, J., Stucky, G. D., Bowers, J., Kim, W.: High Thermoelectric Performance of a Heterogeneous PbTe Nanocomposite. Chem. Mater. 27, 944-999 (2015).

5. Terasaki, I., Sasago, Y., Uchinokura, K.: Large thermoelectric power in $\mathrm{NaCo}_{2} \mathrm{O}_{4}$ single crystals. Phys. Rev. B 56, 12685-12687 (1997).

6. Sotelo, A., Torres, M. A., Constantinescu, G., Rasekh, Sh., Diez, J. C., Madre, M. A.: Effect of $\mathrm{Ag}$ addition on the mechanical and thermoelectric performances of annealed $\mathrm{Bi}_{2} \mathrm{Sr}_{2} \mathrm{Co}_{1.8} \mathrm{O}_{\mathrm{x}}$ textured ceramics. J. Eur. Ceram. Soc. 32, 3745-3751 (2012).

7. Abdellahi, M., Bahmanpour, M., Bahmanpour, M.: Modeling Seebeck coefficient of $\mathrm{Ca}_{3-x} \mathrm{M}_{x} \mathrm{Co}_{4} \mathrm{O}_{9}(\mathrm{M}=\mathrm{Sr}, \mathrm{Pr}, \mathrm{Ga}, \mathrm{Ca}, \mathrm{Ba}, \mathrm{La}, \mathrm{Ag})$ thermoelectric ceramics. Ceram. Int. 41, 345-352 (2015).

8. Funahashi, R., Matsubara, I., Ikuta, H., Takeuchi, T., Mizutani, U., Sodeoka, S.: An Oxide Single Crystal with High Thermoelectric Performance in Air. Jpn. J. Appl. Phys. 39, L1127-L1129 (2000). 
9. Rasekh, Sh., Constantinescu, G., Torres, M. A., Madre, M. A., Diez, J. C., Sotelo, A.: Growth rate effect on microstructure and thermoelectric properties of melt grown $\mathrm{Bi}_{2} \mathrm{Ba}_{2} \mathrm{Co}_{2} \mathrm{O}_{x}$ textured ceramics. Adv. Appl. Ceram. 111, 490-494 (2012).

10. Wang, H., Sun, X., Yan, X., Huo, D., Li, X., Li, J.-G., Ding, X.: Fabrication and thermoelectric properties of highly textured $\mathrm{Ca}_{9} \mathrm{Co}_{12} \mathrm{O}_{28}$ ceramic. J. Alloys Compds. 582, 294-298 (2014).

11. Butt, S., Liu, J.-L., Shehzad, K., Zhan, B., Lin, Y., Nan, C.-W.: High-temperature thermoelectric properties of $\mathrm{La}$ and Fe co-doped $\mathrm{Ca}-\mathrm{Co}-\mathrm{O}$ misfit-layered cobaltites consolidated by spark plasma sintering. J. Alloys Compds. 588, 277-283 (2014).

12. Sotelo, A., Rasekh, Sh., Constantinescu, G., Torres, M. A., Madre, M. A., Diez, J. C.: Improvement of textured $\mathrm{Bi}_{1.6} \mathrm{~Pb}_{0.4} \mathrm{Sr}_{2} \mathrm{Co}_{1.8} \mathrm{O}_{\mathrm{x}}$ thermoelectric performances by metallic Ag additions. Ceram. Int. 39, 1597-1602 (2013).

13. Costa, F. M., Ferreira, N. M., Rasekh, Sh., Fernandes, A. J. S., Torres, M. A., Madre, M. A., Diez, J. C., Sotelo, A.: Very Large Superconducting Currents Induced by Growth Tailoring. Cryst. Growth Des. 15, 2094-2101 (2015).

14. Sun, N., Dong, S. T., Zhang, B. B., Chen, Y. B., Zhou, J., Zhang, S. T., Gu, Z. B., Yao, S. H., Chen, Y. F.: Intrinsically modified thermoelectric performance of alkaline-earth isovalently substituted $\left[\mathrm{Bi}_{2} \mathrm{AE}_{2} \mathrm{O}_{4}\right]\left[\mathrm{CoO}_{2}\right]_{y}$ single crystals. J. Appl. Phys. 114, 043705 (2013).

15. Constantinescu, G., Rasekh, Sh., Torres, M. A., Diez, J. C., Madre, M. A., Sotelo, A.: Effect of $\mathrm{Sr}$ substitution for $\mathrm{Ca}$ on the $\mathrm{Ca}_{3} \mathrm{Co}_{4} \mathrm{O}_{9}$ thermoelectric properties. J. Alloys Compds. 577, 511-515 (2013).

16. Pinitsoontorn, S., Lerssongkram, N., Keawprak, N., Amornkitbamrung, V.: Thermoelectric properties of transition metals-doped $\mathrm{Ca}_{3} \mathrm{Co}_{3.8} \mathrm{M}_{0.2} \mathrm{O}_{9+\delta}(\mathrm{M}=\mathrm{Co}, \mathrm{Cr}$, Fe, Ni, Cu and Zn). J. Mater. Sci.: Mater. Electron. 23, 1050-1056 (2012). 
17. Koshibae, W., Tsutsui, K., Maekawa, S.: Thermopower in cobalt oxides. Phys. Rev. B 62, 6869-6872 (2000).

18. Rubesova, K., Hlasek, T., Jakes, V., Huber, S., Hejtmanek, J., Sedmidubsky,

D.: Effect of a powder compaction process on the thermoelectric properties of $\mathrm{Bi}_{2} \mathrm{Sr}_{2} \mathrm{Co}_{1.8} \mathrm{O}_{x}$ ceramics. J. Eur. Ceram. Soc. 35, 525-531 (2015).

19. Sotelo, A., Constantinescu, G., Rasekh, Sh., Torres, M. A., Diez, J. C., Madre, M. A.: Improvement of thermoelectric properties of $\mathrm{Ca}_{3} \mathrm{CO}_{4} \mathrm{O}_{9}$ using soft chemistry synthetic methods. J. Eur. Ceram. Soc. 32, 2415-2422 (2012).

20. Noudem, J. G., Kenfaui, D., Chateigner, D., Gomina, M.: Granular and Lamellar Thermoelectric Oxides Consolidated by Spark Plasma Sintering. J. Electron. Mater. 40, 1100-1106 (2011).

21. Sotelo, A., Rasekh, Sh., Torres, M. A., Bosque, P., Madre, M. A., Diez, J. C.: Effect of synthesis methods on the $\mathrm{Ca}_{3} \mathrm{Co}_{4} \mathrm{O}_{9}$ thermoelectric ceramic performances. J. Solid State Chem. 221, 247-254 (2015).

22. Madre, M. A., Rasekh, Sh., Touati, K., Salvador, C., Depriester, M., Torres, M. A., Bosque, P., Diez, J. C., Sotelo, A.: From nanosized precursors to high performance ceramics: The case of $\mathrm{Bi}_{2} \mathrm{Ca}_{2} \mathrm{Co}_{1.7} \mathrm{O}_{x}$. Mater. Lett. 191, 14-16 (2017).

23. Rasekh, Sh., Sotelo, A., Torres, M. A., Bosque, P., Madre, M. A., Diez, J. C.: Thermoelectric properties of directionally grown $\mathrm{Bi}_{2} \mathrm{Ba}_{2} \mathrm{Co}_{2} \mathrm{O}_{\delta} / \mathrm{Ag}$ composites: effect of annealing. J. Mater. Sci. Mater. Electron. 27, 12964-12973 (2016).

24. Chemistry WebBook of NIST. http://webbook.nist.gov/chemistry/.

25. Diez, E., Monnereau, O., Tortet, L., Vacquier, G., Llewellin, P., Rouquerol, F.: Synthesis of bismuth (iii) oxide from oxalate: a study by controlled transformation rate thermal analysis (CRTA). J. Optoelectron. Adv. Mater. 2, 552-556 (2000). 
26. Hao, H., Yang, H., Liu, Y., Hu, X.: High-temperature Thermoelectric Properties of Cu-substituted $\mathrm{Bi}_{2} \mathrm{Ba}_{2} \mathrm{Co}_{2-x} \mathrm{Cu}_{x} \mathrm{O}_{y}$ Oxides. J. Mater. Sci. Technol. 27, 525-528 (2011).

27. Diez, J. C., Madre, M. A., Torres, M. A., Rasekh, Sh., Sotelo, A.: Long-Term High-Temperature Stability of Directionally Grown $\left[\mathrm{Bi}_{2} \mathrm{Ba}_{2} \mathrm{O}_{4}\right]_{[}\left[\mathrm{CoO}_{2}\right]$ Rods. Materials 10, 146 (2017).

28. Sotelo, A., Rasekh, Sh., Madre, M. A., Guilmeau, E., Marinel, S., Diez, J. C.: Solution-based synthesis routes to thermoelectric $\mathrm{Bi}_{2} \mathrm{Ca}_{2} \mathrm{Co}_{1.7} \mathrm{O}_{x}$. J. Eur. Ceram. Soc. 31, 1763-1769 (2011).

29. Sakai, K., Motohashi, T., Karppinen, M., Yamauchi, H.: Enhancement in thermoelectric characteristics of the misfit-layered cobalt oxide, $[(\mathrm{Bi}$, $\left.\mathrm{Pb})_{2} \mathrm{Ba}_{1.8} \mathrm{Co}_{0.2} \mathrm{O}_{4 \pm x}\right]_{0.5} \mathrm{CoO}_{2}$, through Pb-for-Bi substitution. Thin Solid Films 486, 58$62(2005)$.

30. Hao, H., Yu, H., Zhao, L.: Thermoelectric characteristics of Pb- and La-doped $\mathrm{Bi}_{2} \mathrm{Ba}_{2} \mathrm{Co}_{2} \mathrm{O}_{\mathrm{y}}$ ceramics. Adv. Mater. Res. 228-229, 804-808 (2011).

31. Constantinescu, G., Rasekh, Sh., Torres, M. A., Madre, M. A., Diez, J. C., Sotelo, A.: Enhancement of the high-temperature thermoelectric performance of $\mathrm{Bi}_{2} \mathrm{Ba}_{2} \mathrm{Co}_{2} \mathrm{O}_{x}$ ceramics. Scr. Mater. 68, 75-78 (2013).

32. Motohashi, T., Nonaka, Y., Sakai, K., Karppinen, M., Yamauchi, H.: Fabrication and thermoelectric characteristics of $\left[(\mathrm{Bi}, \mathrm{Pb})_{2} \mathrm{Ba}_{2} \mathrm{O}_{4 \pm x}\right]_{0.5} \mathrm{CoO}_{2}$ bulks with highly aligned grain structure. J. Appl. Phys. 103, 033705 (2008).

33. Madre, M. A., Costa, F. M., Ferreira, N. M., Costa, S. I. R., Rasekh, Sh., Torres, M. A., Diez, J. C., Amaral, V. S., Amaral, J. S., Sotelo, A.: High thermoelectric performance in $\mathrm{Bi}_{2-x} \mathrm{~Pb}_{x} \mathrm{Ba}_{2} \mathrm{Co}_{2} \mathrm{O}_{y}$ promoted by directional growth and annealing. J. Eur. Ceram. Soc. 36, 67-74 (2016). 
34. Kobayashi, W., Hebert, S., Muguerra, H., Grebille, D., Pelloquin, D., Maignan, A.: Thermoelectric properties in the misfit-layered-cobalt oxides $\left[\mathrm{Bi}_{2} \mathrm{~A}_{2} \mathrm{O}_{4}\right]\left[\mathrm{CoO}_{2}\right]_{\mathrm{b} 1 / \mathrm{b} 2}$ $(\mathrm{A}=\mathrm{Ca}, \mathrm{Sr}, \mathrm{Ba}, \mathrm{b} 1 / \mathrm{b} 2=1.65,1.82,1.98)$ single crystals. In: Kim, I.-H. (ed) Proceedings ICT'07, pp 117-120. IEEE, Piscataway, (2008).

35. Luo, X. G., Chen, H., Wang, G. Y., Wu, G., Wu, T., Zhao, L., Chen, X. H.: Transport properties and magnetic-field-induced localization in the misfit cobaltite $\left[\mathrm{Bi}_{2} \mathrm{Ba}_{1.3} \mathrm{~K}_{0.6} \mathrm{Co}_{0.1} \mathrm{O}_{4}\right]^{\mathrm{RS}}\left[\mathrm{CoO}_{2}\right]_{1.97}$ single crystal. J. Phys.: Condens. Matter. 20, $215221(2008)$.

36. Madre, M. A., Rasekh, Sh., Torres, M. A., Bosque, P., Diez, J. C., Sotelo, A.: Enhanced electrical and thermoelectric properties from textured $\mathrm{Bi}_{1.6} \mathrm{~Pb}_{0.4} \mathrm{Ba}_{2} \mathrm{Co}_{2} \mathrm{O}_{\mathrm{y}} / \mathrm{Ag}$ composites. J. Mater. Sci. 52, 4833-4839 (2017). 
Table 1: Electrical resistivity, Seebeck coefficient, and power factor obtained in the different samples, and in the literature.

\begin{tabular}{|c|c|c|c|c|c|c|}
\hline \multirow[t]{2}{*}{ Material } & \multicolumn{2}{|c|}{$\rho(\mathrm{m} \Omega . \mathrm{cm})$} & \multicolumn{2}{|c|}{$\mathrm{S}(\mu \mathrm{V} / \mathrm{K})$} & \multicolumn{2}{|c|}{$P F\left(m W / K^{2} m\right)$} \\
\hline & RT & $650^{\circ} \mathrm{C}$ & RT & $650^{\circ} \mathrm{C}$ & RT & $650^{\circ} \mathrm{C}$ \\
\hline P1 & 13.2 & 17.5 & 103 & 187 & 0.08 & 0.20 \\
\hline P2 & 13.6 & 26.4 & 100 & 186 & 0.07 & 0.13 \\
\hline P3 & 42.6 & 51.9 & 105 & 188 & 0.03 & 0.07 \\
\hline Sintered $[29,30]$ & $550-21$ & 33 & $85-87$ & 118 & $0.01-0.04$ & 0.04 \\
\hline Textured [9,31-33] & $250-10$ & $8.5-16$ & $115-143$ & $150-190$ & $0.03-0.15$ & $0.16-0.40$ \\
\hline Single crystal $[34,35]$ & $4-10$ & ---- & 110 & ---- & $0.12-0.30$ & ---- \\
\hline
\end{tabular}




\section{Figure captions}

Figure 1. FTIR spectra of precursors in different preparation steps: a) P1 dry precipitate; b) P1 after thermal treatment at $450^{\circ} \mathrm{C}$; c) P3 after thermal treatment at $700^{\circ} \mathrm{C}$; d) P2 after thermal treatment at $700^{\circ} \mathrm{C}$; and e) P2 after thermal treatment at $750^{\circ} \mathrm{C}$.

Figure 2. SEM micrographs of precursors powders: a) dry P1 precipitate; b) P1 after thermal treatment at $450^{\circ} \mathrm{C}$; c) dry P2; and d) dry P3.

Figure 3. SEM micrographs of precursor powders after calcining procedure: a) P1; b) P2 and c) P3.

Figure 4. Powder XRD plots of the $\mathrm{Bi}_{2} \mathrm{Ba}_{2} \mathrm{Co}_{2} \mathrm{O}_{x}$ sintered bodies prepared from the different synthesis methods. a) P1; b) P2; and c) P3. Crystallographic planes indicate the peaks for the $\mathrm{Bi}_{2} \mathrm{Ba}_{2} \mathrm{Co}_{2} \mathrm{O}_{x}$ phase.

Figure 5. SEM micrographs obtained on polished sections of sintered materials prepared from the different precursors P1 (a), P2 (b), and P3 (c). Numbers indicate the different phases: \#1 grey, $\mathrm{Bi}_{2} \mathrm{Ba}_{2} \mathrm{Co}_{2} \mathrm{O}_{x}$; $\# 2$ black, Co-oxide; \#3 light grey, $\mathrm{BiBa}-$ oxide; and \#4 dark grey, BaCo-oxide.

Figure 6. Variation of electrical resistivity with temperature for sintered materials prepared from the different precursors $(\bullet) P 1,(\square) P 2$, and $(\bullet)$ P3.

Figure 7. Variation of Seebeck coefficient with temperature for sintered materials prepared from the different precursors $(\bullet) \mathrm{P} 1,(\square) \mathrm{P} 2$, and $(\bullet)$ P3.

Figure 8. Power factor vs. temperature of sintered materials prepared from the different precursors $(\diamond) \mathrm{P} 1,(\square) \mathrm{P} 2$, and $(\bullet)$ P3. 
Figure 1

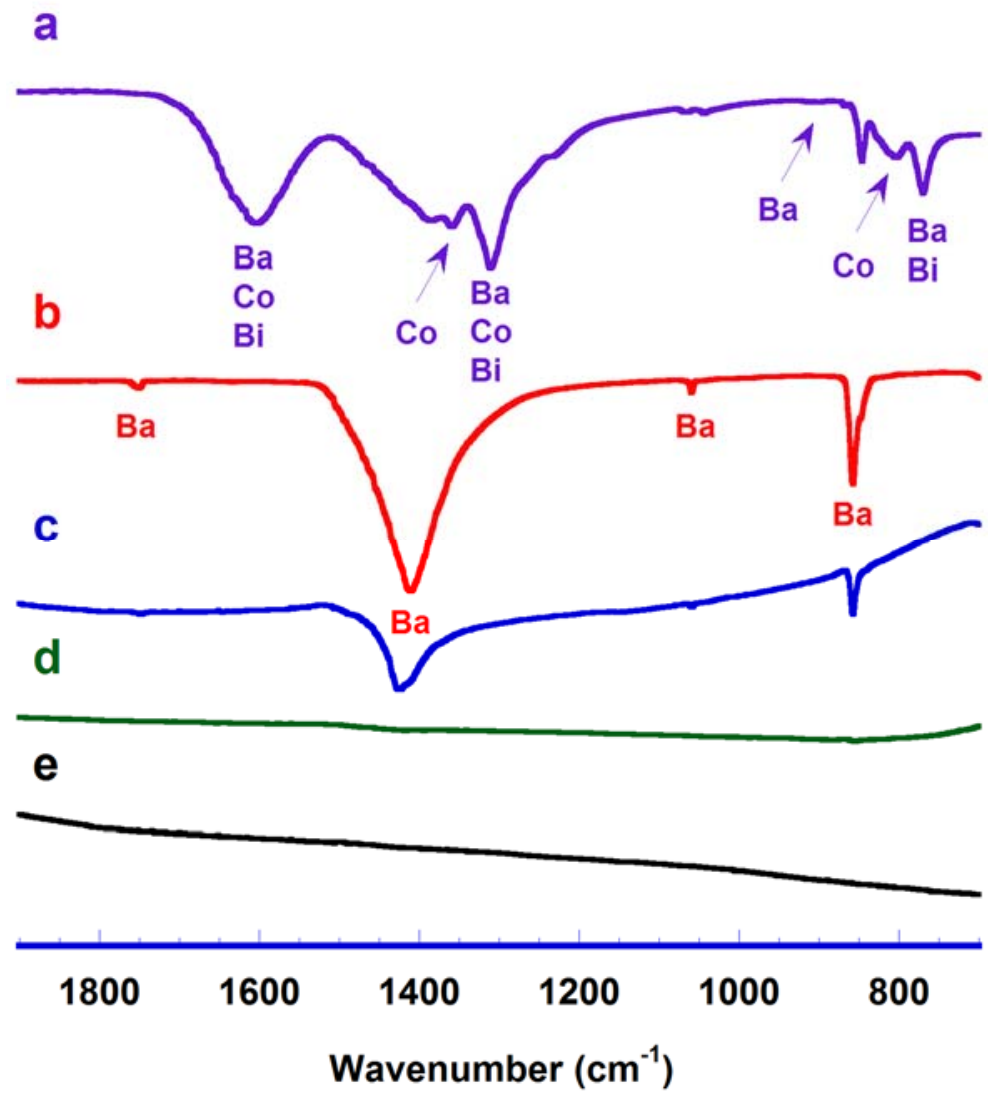


Figure 2
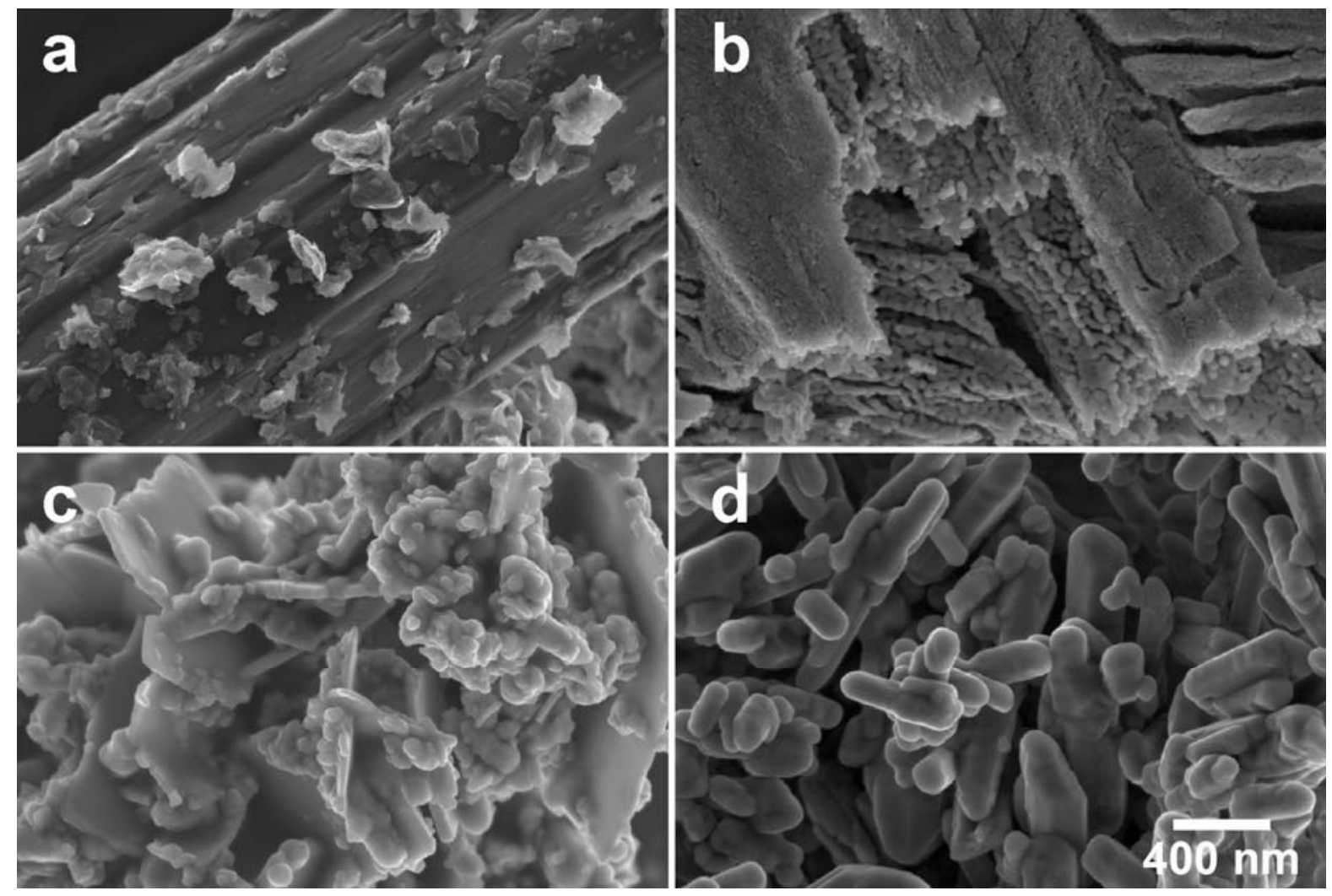
Figure 3
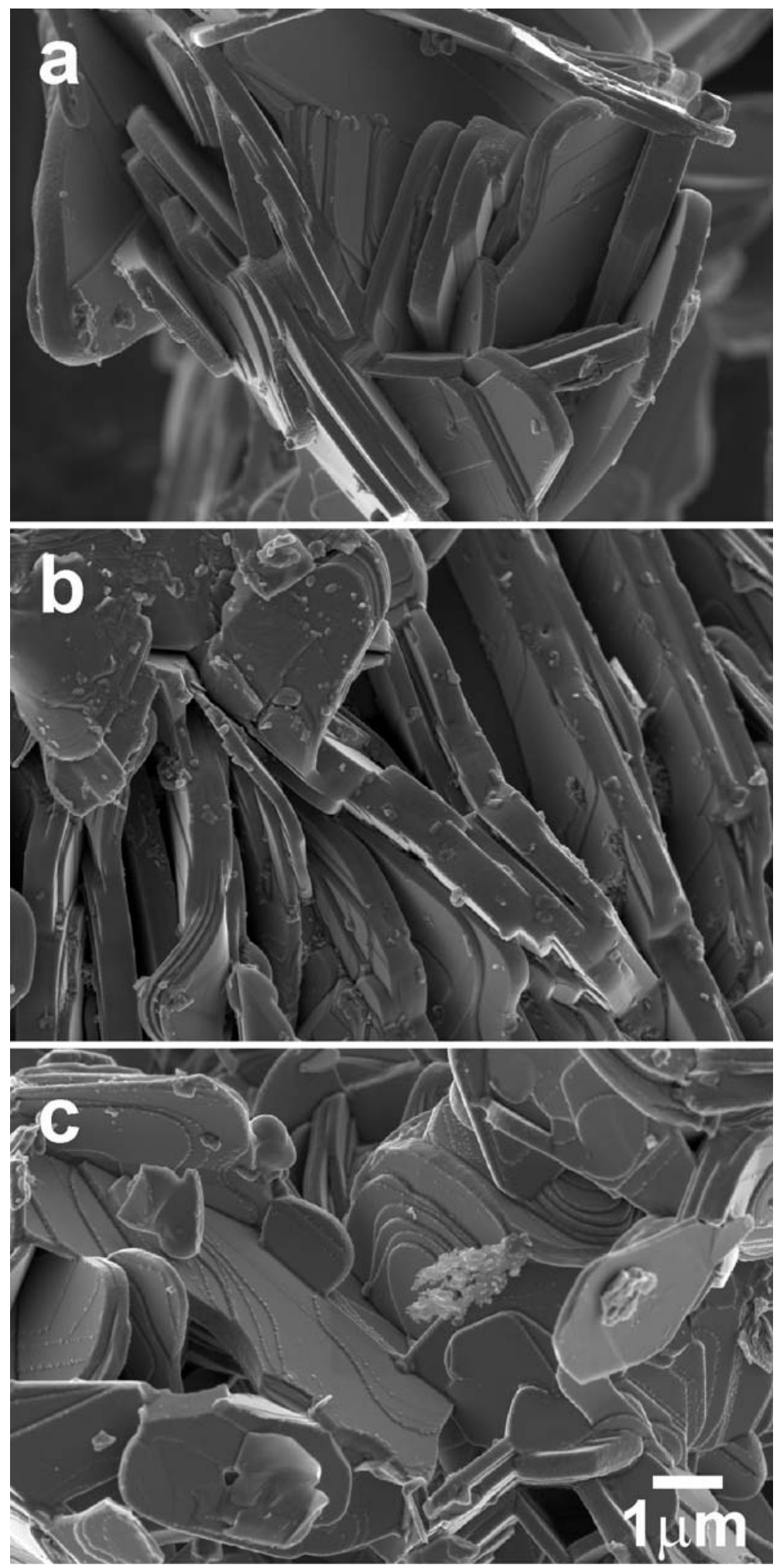
Figure 4

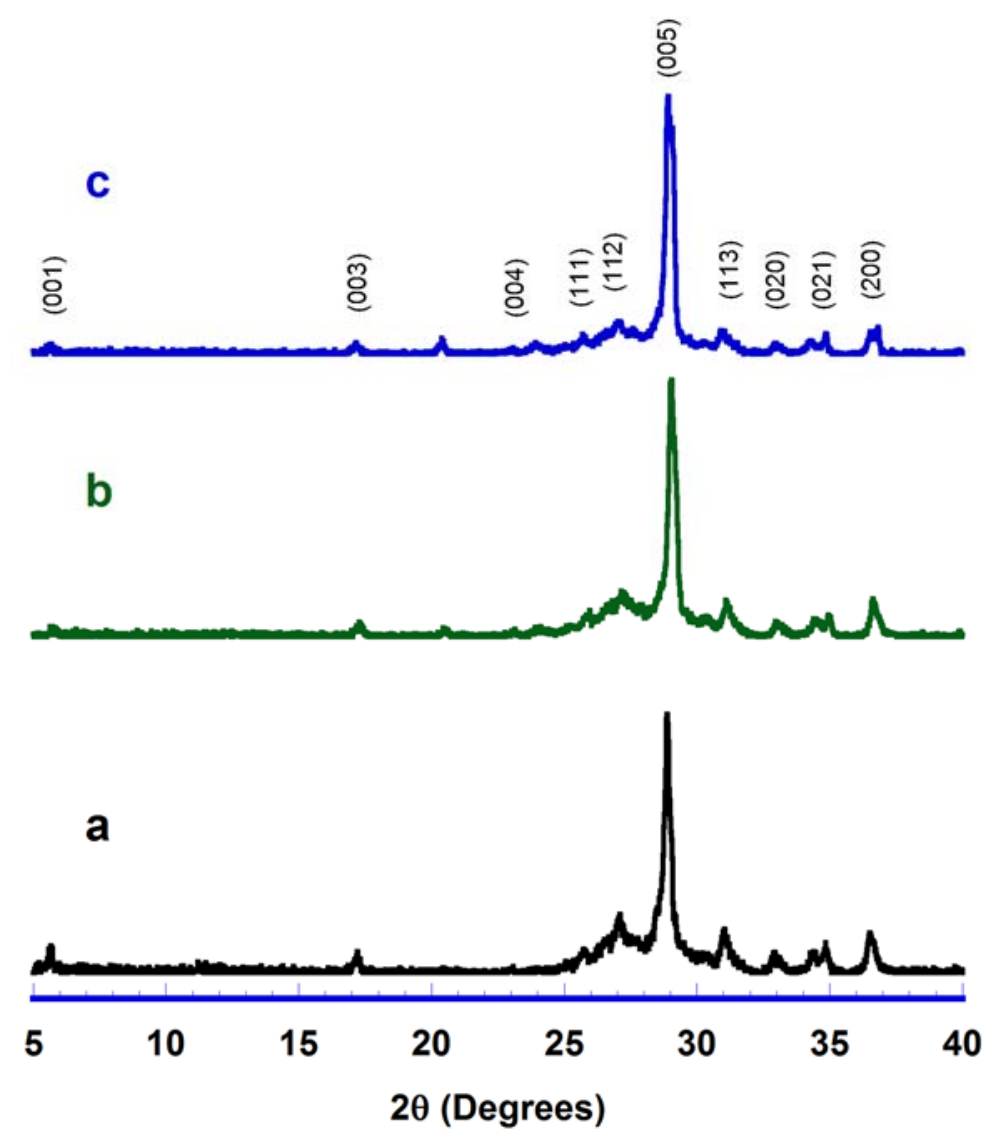


Figure 5
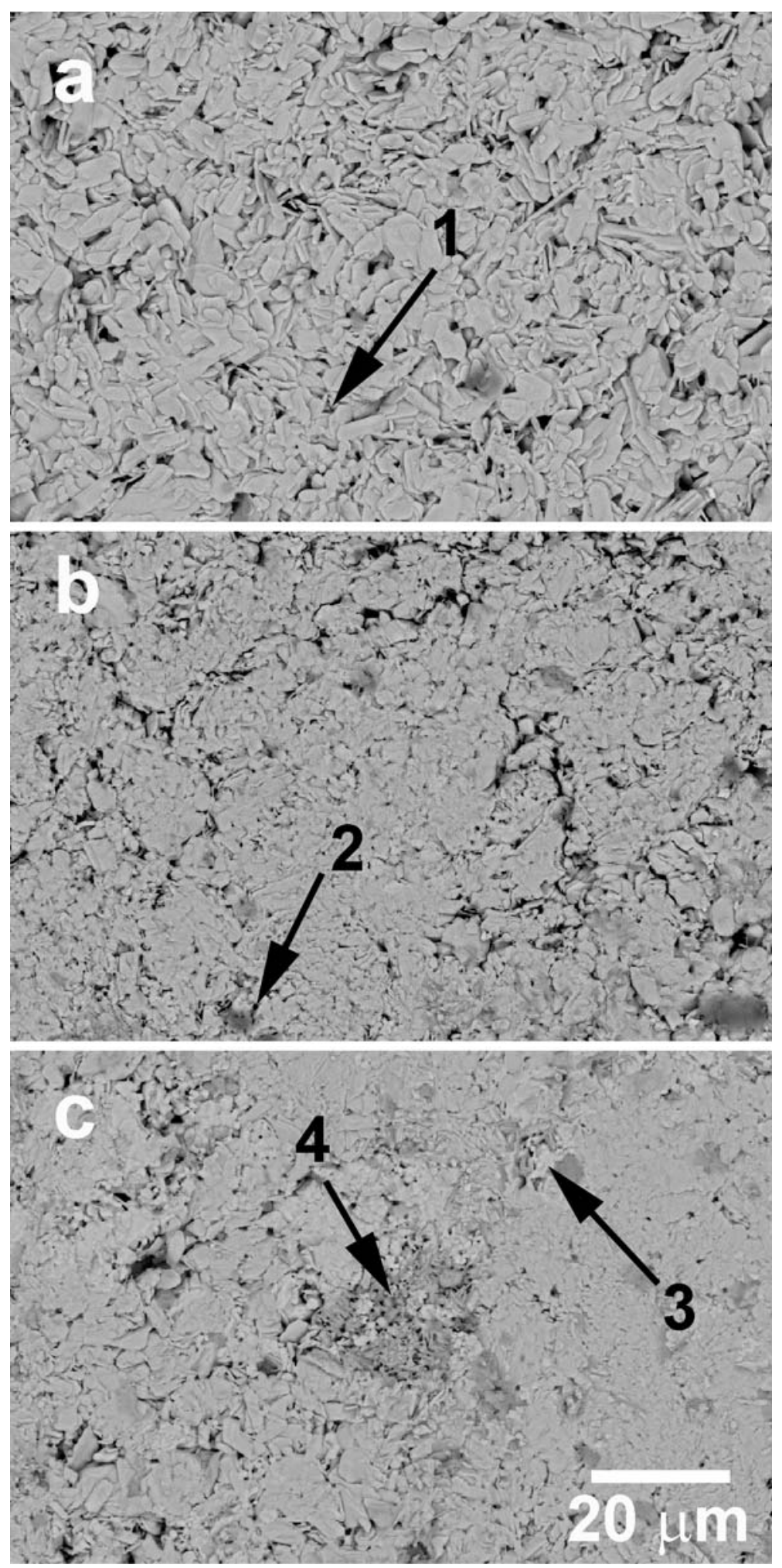
Figure 6

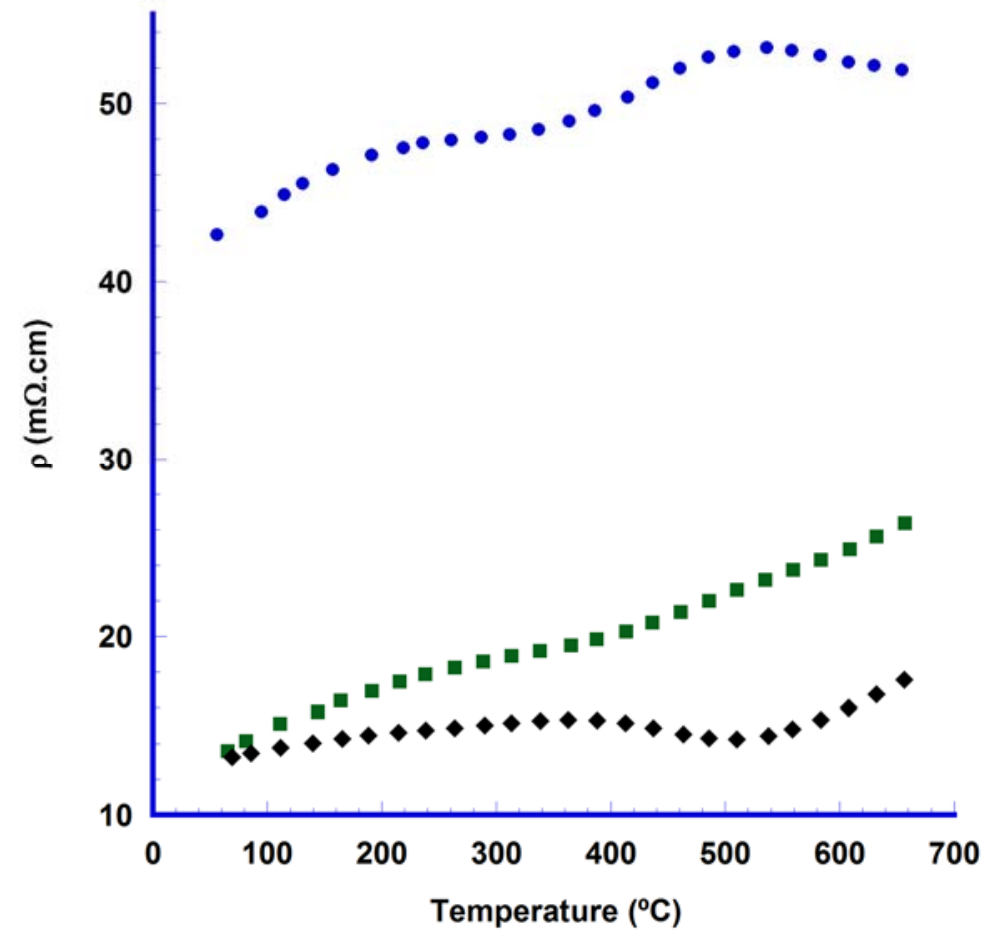


Figure 7

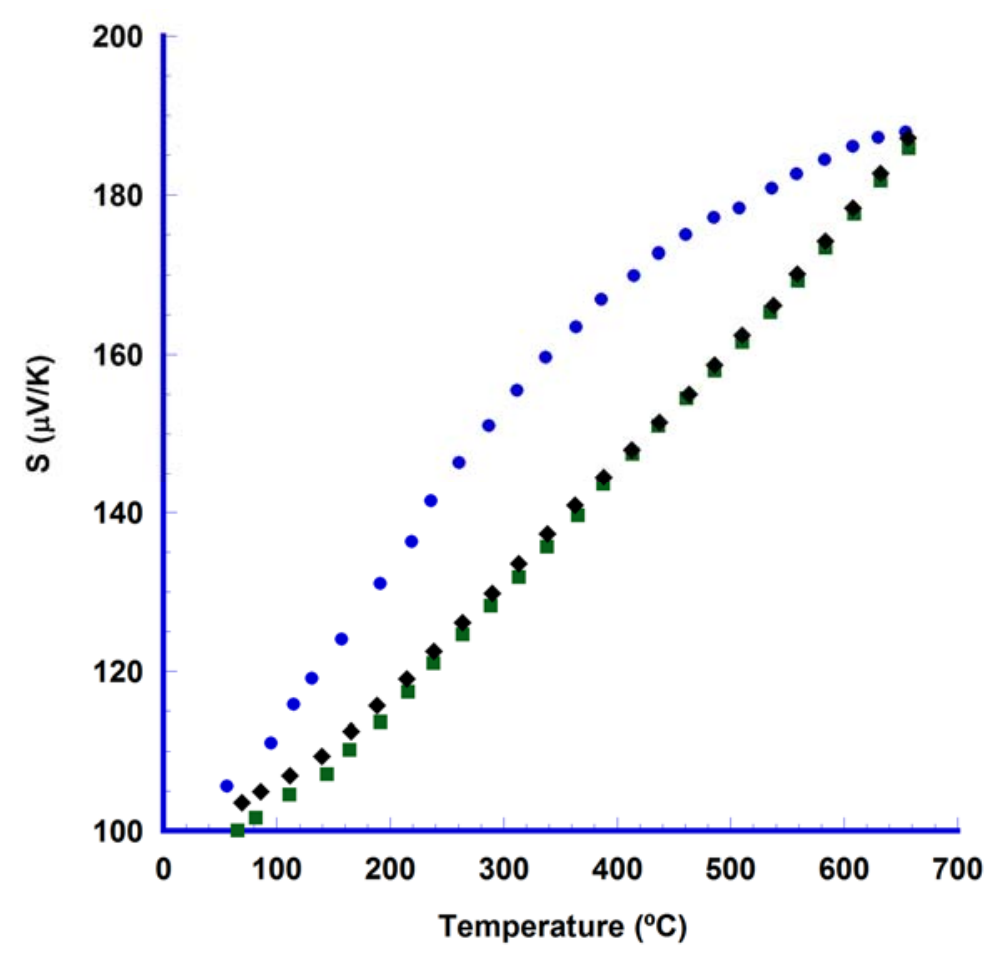


Figure 8

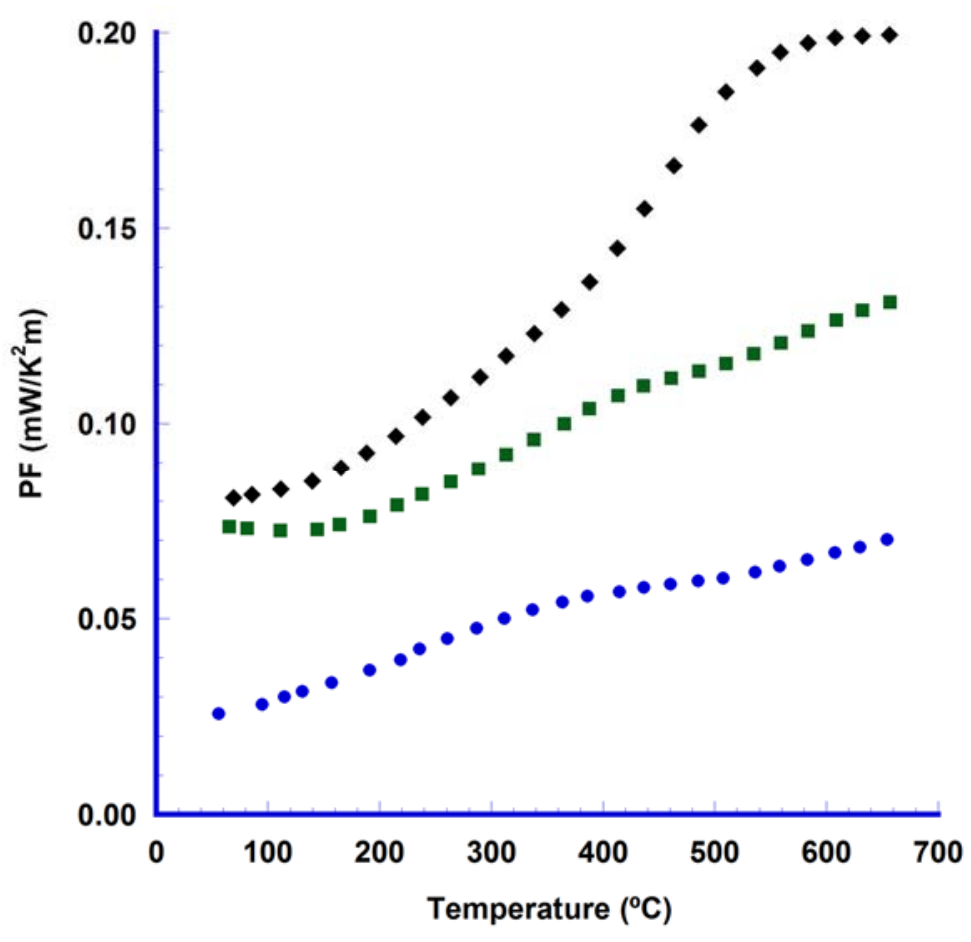

